\title{
Comparative study of post-intervention soreness between dry needling and percutaneus needle electrolysis
}

\author{
Ciórraga López J. L. ${ }^{1}$ Vega Moreu P. ${ }^{1}$ \\ ${ }^{1}$ C.F. Rayo Majadahonda, Madrid, Spain \\ Rev Fisioter Invasiva 2019;2:64.
}

\begin{abstract}
\section{Keywords}

- myofascial pain syndrome

- post-needling pain

- dry needling

- percutaneous needle electrolysis

Aims The aim of this research was to study the appearance of soreness after dry needling (DN) and percutaneous needle electrolysis (PNE) in latent trigger points of the extensor muscle of the posterior forearm region.

Material and Methods A pre-test/post-test pilot study was performed, in which 15 volunteers with latent trigger points in the extensor muscles of the posterior forearm region were randomly distributed into a group $A$ who received treatment with $D N$ and a group B who received treatment with PNE. Before and after the intervention, algometry measurements were performed at the site where the trigger point was found, and, after the intervention the patient was asked to complete two visual analog scales (VAS) to evaluate pain during the intervention and a second scale to measure pain once the needle had been removed. In addition, the same scale was performed after 24 hours, 72 hours, and 1 week after the dry needling. The statistical analysis was performed using the SPSS program version 24.0, evaluating the normality of the variables using the Shapiro-Wilk test, as the sample was less than 50 subjects. P values of $>0.05$ were considered normal.

Results The ANOVA revealed a significant effect for time on the decrease of the VAS scores, both in the groups of dry needling $(P<0.001)$, as well as in the group of PNE $(P<0.001)$. In contrast, a group-time interaction was not observed $(P=0.824)$, ruling out statistically significant differences between the DN group and the PNE group. The Student's t-test showed a significantly decreased pain pressure threshold between the pre and post algometry, both in the group of $D N(P<0.001)$ and the group of PNE $(P<0.003)$. However, no statistically significant differences were found between both groups in pre and post algometry $(P=0.457)$.

Conclusion All patients presented post-needling soreness, without significant differences between DN and PNE interventions. The most intense pain was registered minutes after the dry needling, which then decreased without significant differences, reaching 0 after 72 hours, in most cases. Neither of the two techniques caused increased pain in response to pressure in a significantly different manner. No relationship was observed between a greater number of LTRs and post-needling pain. There was a correlation between pain experienced during the intervention and pain 24 hours after the needling. The levels of post-intervention pain secondary to the application of DN and PNE in latent trigger points of the extensor muscles of the posterior forearm region did not present significant differences among study subjects in both intervention groups.
\end{abstract}

Copyright $\odot 2019$ by Thieme Revinter

Publicações Ltda, Rio de Janeiro, Brazil
License terms

(®) $\Theta \circledast$ 